Citation: Golub, K., \& Lund, A. (2021). Why open government data? The case of a Swedish municipality. Journal of Data and Information Science, 6(1), 120-138. https://doi.org/10.2478/ jdis-2021-0012

Received: Jun. 15, 2020

Revised: Oct. 10, 2020

Accepted: Nov. 2, 2020

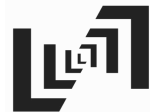

JDIS

Journal of Data and Information Science

\section{Why Open Government Data? The Case of a Swedish Municipality}

\author{
Koraljka Golub $^{1 \dagger}$, Arwid Lund ${ }^{2}$ \\ ${ }^{1}$ Linnaeus University, 35195 Växjö, Sweden \\ ${ }^{2}$ Södertörn University, 14189 Huddinge, Stockholm, Sweden
}

\begin{abstract}
Purpose: The purpose of this exploratory study is to provide modern local governments with potential use cases for their open data, in order to help inform related future policies and decision-making. The concrete context was that of the Växjö municipality located in southeastern Sweden.
\end{abstract}

Design/methodology/approach: The methodology was two-fold: 1) a survey of potential end users ( $\mathrm{n}=151)$ from a local university; and, 2) analysis of survey results using a theoretical model regarding local strategies for implementing open government data.

Findings: Most datasets predicted to be useful were on: sustainability and environment; preschool and school; municipality and politics. The use context given is primarily research and development, informing policies and decision making; but also education, informing personal choices, informing citizens and creating services based on open data. Not the least, the need for educating target user groups on data literacy emerged. A tentative pattern comprising a technical perspective on open data and a social perspective on open government was identified.

Research limitations: In line with available funding, the nature of the study was exploratory and implemented as an anonymous web-based survey of employees and students at the local university. Further research involving (qualitative) surveys with all stakeholders would allow for creating a more complete picture of the matter.

Practical implications: The study determines potential use cases and use contexts for open government data, in order to help inform related future policies and decision-making.

Originality/value: Modern local governments, and especially in Sweden, are faced with a challenge of how to make their data open, how to learn about which types of data will be most relevant for their end users and what will be different societal purposes. The paper contributes to knowledge that modern local governments can resort to when it comes to attitudes of local citizens to open government data in the context of an open government data perspective.

Keywords Open data; E-government; Open government

Corresponding author: Koraljka Golub (E-mail: koraljka.golub@lnu.se). 


\section{Introduction}

In the digital world that we live in governments enforce laws and regulations to make data and information they produce available for free use and reuse, thus ensuring public participation (HM Treasury, 2009; Gruen, 2009; White House, 2009a; 2009b). These data may be utilized by various stakeholders to gain new knowledge, as well as to create and provide new services and products for citizens, businesses and governments. The latter can in turn lead to new industries and increased employment rates (Manyika et al., 2013; Ubaldi, 2013). From the viewpoint of social activists and the citizenry, open government (OG) holds the promise of ensuring not only public participation but also actual collaborations with citizens and community-based NGOs (Non-Governmental Organizations) for common goals, thus deepening the democratic processes (Baack, 2015; Kalin, 2014; Lee \& Hoon Kwak, 2011; Milan \& Gutiérrez, 2015). The Swedish government committed to re-use of public administration documents and open data in 2016 (Shekarabi \& Aldén, 2016; Open Government Partnership, 2018).

These laws, regulations, and visions regarding OG are differently organized and unevenly implemented internationally. OECD (2019) surveys the digital government strategy of its member states and 44\% locate the governing body within the center of government, $23 \%$ have a line ministry as responsible, and $33 \%$ give a specific governmental agency a co-ordinating and advisory authority. Sweden falls into this third category. Riksarkivet (The National Archive) was the responsible agency from 2016 until 2019 when it was substituted by the Agency for Digital Government (Myndigheten för digital förvaltning) (DIGG, 2019a). Sweden, to conclude, is not a leading OGD-actor internationally. The country rather places itself in the lower end of the spectra in relation to the use of centralised standardised policy, and especially so in relation to the availability of open and accessible data, and the government's support for data re-use (OECD, 2019). In 2015 Frick (2015) contended that it was hard to get an overview over the Swedish OD-landscape as no responsible body was yet appointed, but mentions that SMHI, the Swedish Meteorological and Hydrological Institute, was an early adopter and released open data in 2013. That was only one year after the Swedish government assigned the task of building a national OD Portal to Vinnova (DIGG, 2019b). But since 2019, the Agency for Digital Govenment recommends openness in relation to copyright, formats, and APIs. Copyright licenses should not unnecessarily limit the reuse, the quality of the data and meta-data should be checked, and the OD portals should strive to integrate platform with the users' need and stimulate the use of the data (DIGG, 2020). The work on how to implement the Open Data EU Directive from 2003 is also progressing with new inquiries recently published (Liljeqvist et al., 2020).

Journal of Data and Information Science

http://www.jdis.org https://www.degruyter.com/view/j/jdis 


\section{Research Paper}

In effect, modern local governments, and especially in Sweden, are faced with a challenge of how to make their data open, how to learn about which types of data will be most relevant for their end users and what will be different societal purposes. Related research seems to represent a mixture of technical project reports and scientific research on OG, open government data (OGD), big data, and their general role for democracy and economy, including quality and ethics of data and their implications. However, less attention seems to have been paid to creating evidencebased policies for the implementation of local open government data initiatives. For example, Hossain and Chan (2015) point to the need for governmental guidelines on OGD and propose that the guidelines are discussed with researchers as a potential user group. Safarov, Meijer, and Grimmelikhuijsen (2017) observe that the majority of studies on open government data seem to assume, rather than empirically determine, forms of utilization of the data. Weerakkody et al. (2017) also point to the lack of empirical analyses in terms of OGD acceptance.

The ultimate purpose of the paper is to contribute to knowledge that modern local governments can resort to when it comes to attitudes of local citizens to OGD in the context of an OG perspective. It sets out to determine potential use cases and use contexts for their open data, in order to help inform related future policies and decision-making. The concrete context is that of Växjö municipality (located in Växjö, population of about 90,000). The local OGD portal, online since 2017, publishes the data under Creative Commons CC BY-license. The methodology comprised: 1) a survey of potential end users working and studying at Linnaeus University situated in the municipalities of Växjö and Kalmar; and, 2) a subsequent analysis of survey results using a theoretical model based on the empirical findings of Lassinanti, Bergvall-Kåreborn, and Stålbröst (2014), regarding local strategies for implementing open government data.

The reminder of the paper is structured as follows: first, the related research section presents a brief overview of surveys related to the use of OGD. The methodology section describes aims, sample, survey instrument, and model for analysis. What follows is a presentation and a discussion of results, including an analysis based on the model. Finally, the concluding section discusses major implications and proposes future work.

\section{Related research}

Governments have always collected and analysed information to deliver services to the citizens, but now they have to think also about what citizens and users would find valuable in the data and information that government possesses (Harrison, Pardo, \& Cook, 2012) as well as how to present and make the data available for the 
end users. Hossain and Chan (2015) discuss OGD in Australia and point to the need for governmental guidelines on OGD whereby they propose that the guidelines are discussed with researchers as a potential user group. They also establish that the data should be made available in different formats in order to cater for varied user groups, albeit subject to available resources in the government agency, the latter being seen as one of major obstacles to making OGD available.

Safarov, Meijer, and Grimmelikhuijsen (2017) analyse over a hundred academic studies on OGD utilization and provide an overview of types of OGD utilization, effects of utilization, key conditions, and different users. They observe that the majority of studies seem to assume, rather than empirically determine, forms of utilization. They contend that the link between type of utilization, type of users and type of effects or outcomes must be explored further. An example of an exception whereby forms of utilization are empirically determined is work by Martin, Helbig, and Birkhead (2015) who conducted a focus group survey with researchers and practitioners on potential uses of open health data and New York's open data strategy. While the majority of the participants have never used an open data portal before, they consider certain data sets potentially useful. They also ask for the option to link multiple datasets as well as that the data be structured in different formats for different uses.

Gascó-Hernández et al. (2018) recognize the lack of OGD uptake as partly attributable to the lack of technical skills and user training. They have therefore implemented three training interventions in Spain, Italy, and the United States in order to increase awareness of OGD, improve users' skills and engage them into using OGD, concluding that awareness alone is insufficient and needs to be complemented by OGD training, ideally in line with users' needs and interests.

Weerakkody et al. (2017) also point to the lack of empirical analyses in terms of public sector open data acceptance. Through a questionnaire of 350 respondents, they investigate British users' behavioural intentions through the impact of perceived usefulness, perceived ease of use, and social approval (derived from the technology acceptance model). Their results point to the conclusion that the form of badly structured raw data is of little potential use to people without appropriate technical knowledge, which ultimately leads to the loss of citizen interest in open government data.

\section{Methodology}

The purpose of the paper is to contribute to knowledge that modern local governments can resort to when it comes to attitudes of local citizens to OGD in the context of an OG perspective. It sets out to determine potential use cases and

Journal of Data and Information Science

http://www.jdis.org https://www.degruyter:com/view/j/jdis 


\section{Research Paper}

use contexts for their open data, in order to help inform related future policies and decision-making. The concrete context is that of Växjö municipality.

Therefore, within an open government perspective, the aims of the study are to:

1. Predict most common uses of data sets which Växjö municipality could make available in the future;

2. Estimate usefulness of existing data sets and usability thereof at Växjö municipality's open data prototype portal; and,

3. Contribute to citizen-informed research/body of literature which can be used to improve the implementation of OGD initiatives.

To address the aims, the methodology comprised: 1) a survey of potential end users working and studying at Linnaeus University situated in the municipalities of Växjö and Kalmar; and, 2) a subsequent analysis of survey results using a theoretical model based on the empirical findings of Lassinanti, Bergvall-Kåreborn, and Stålbröst (2014), regarding local strategies for implementing open government data.

\subsection{Survey}

While use cases for open government data extend the academic environment of a local university, as discussed in the Related research section, it was Linnaeus University researchers and students that were the primary targeted population for the survey. Academia with its open scholarship has made more headway into open data with its aim "to speed the pace of research, to encourage new questions and forms of investigations" than other non-commercial sectors of society (Borgman, 2015). It is highly relevant what this sector expects and desires from local OGD, but it is also a sample selected out of convenience and limited research funding. Still, it is considered that academic researchers present one major potential user group of open government data as data are "inputs, outputs and assets of scholarship" (Borgman, 2015), at the same time as data are in the process of reframing the epistemologies of science, social science and humanities (Kitchin, 2014).

The study was implemented as an anonymous web survey. It was distributed to general employee mailing lists of departments from all five faculties at the university: Faculty of Arts and Humanities, Faculty of Health and Life Sciences, Faculty of Social Sciences, Faculty of Technology, School of Business and Economics. It is not possible to know exactly how many people were reached as these were only mailing lists but at the time there were about 2,000 researchers and teachers employed at the university. Further, the total of 6,205 email addresses of students were randomly chosen, out of some 30,000 registered students. The survey was also advertised at the university's internal web site for employees, so it was open to all 
working at the university, beyond just the five major faculties, such as the University Library employees.

The questionnaire was open for completion from 23 January to 30 April 2017. The first letter of invitation was distributed in the period from 23 January to 26 January 2017; a reminder was sent in the period from 27 March to 30 March 2017. The invitation letter comprised two parts, the top one written in Swedish, followed by the identical one in English. It briefly informed that: the survey was about current and potential needs related to open data generated by Växjö municipality while pointing to a link of the portal for those unfamiliar with open data; it was anonymous; it comprised ten mandatory questions predicted to take about five minutes to complete. Respective URLs to Swedish and English versions of the actual survey were provided at the end of the invitation letter.

The web-based questionnaire comprised 11 questions, of which 10 mandatory ones. There were six multiple-choice questions, and five open-ended ones. Apart from four demographic questions (age, discipline, institution, professional title), the remainder referred to the open data, asking about which categories of data they would find most relevant, how they would use them, usefulness of already available data sets and whether the latter could be presented in a more meaningful / useful way for them, and a final open question on any further comments or suggestions on the municipality's open data. The categories of data were taken to be information categories used on the municipality's website.

The survey was created in collaboration with the municipality. It was pilot-tested with four representatives from the target population; smaller adjustments were made as a result. The questionnaire was administered using Swedish academic survey software called Survey and Report, provided by SUNET (Swedish University Computer Network). Quantitative data analysis was conducted using MS Excel, upon export from Survey and Report. Open ended questions were analysed using content analysis. This included tagging each open-ended reply with one or more categories. The process of recognizing categories across the replies was iterated several times. The categories were then used to present the results in the following section. Due to limited funding available, this was done by one of the authors of the paper.

\subsection{Model of analysis}

A theoretical model to analyse the survey results was used to establish what implications can be drawn, in order to make future approaches to local OGD initiatives more useful. The model is based on empirical findings of Lassinanti, Bergvall-Kåreborn, and Stålbröst (2014), regarding municipal strategies for implementing open government data in two Swedish cities: Skellefteå and

Journal of Data and Information Science

http://www.jdis.org https://www.degruyter.com/view/j/jdis 


\section{Research Paper}

Stockholm. Skellefteå has almost as many inhabitants as Växjö:circa 72,000 people were living in the municipality in the end of 2018. A difference between that study and the present one is that the former focuses on the municipalities as actors while the present one on potential users; however, since these two perspectives present two sides of the same coin, the application of the results from the former study is still appropriate.

The municipality of Stockholm went down the line of open data for commercial uses: "a techno-economic growth that rendered a fast process aiming initially for revenue-driven developers and companies", while the municipality of Skelleftea focused on open data for societal growth: "a co-created societal growth that led to a more elongated and reactive process targeting various citizens in the long run" (ibid., p. 29). These two perspectives on OGD have been formalised, and adapted to the needs of the present study, in the following model:

Table 1. A comparison of two approaches to OGD, derived from Lassinanti, Bergvall-Kårborn, and Ståhlbröst (2014).

\begin{tabular}{|c|c|c|}
\hline & Stockholm local strategy on OGD & Skellefteå local strategy on OGD \\
\hline Target groups & Technical experts and companies & Local community and (young) citizens \\
\hline $\begin{array}{l}\text { Desired practical } \\
\text { outcomes }\end{array}$ & $\begin{array}{l}\text { Development of economically sustainable } \\
\text { and revenue driven services }\end{array}$ & $\begin{array}{l}\text { Empowered citizens' collaboration for public } \\
\text { sector innovation }\end{array}$ \\
\hline General aim & Open data platform for economic growth & $\begin{array}{l}\text { Regional co-operation and co-creation of } \\
\text { social growth }\end{array}$ \\
\hline Strategy & Top-down approach & Broader and more reflective approach \\
\hline
\end{tabular}

To clarify the model further, the target group aspect stresses two opposite ways of perceiving the opening up of OGD. For Stockholm municipality their responsibility for open data ends at the point of publication of the data. After that, it is all up to the data users, understood as companies with the necessary technical expertise. In Skelleftea the publication of open data is instead the start of a longer process with several different stakeholders (ibid., p. 26). The two following aspects are rather straightforward, but the last one on strategy is probably good to expand on. Municipality's strategic management can choose what data sets to release openly in the top-down approach, whereas the alternative approach engages all of the municipality's employees (ibid., p. 26). This strategy aspect correlates in a more general way with the other aspects of the model: a top-down strategy focus on fewer stakeholders within a narrow focus on technical expertise and economic outcomes, and a broader strategy focus on several different stakeholders within a regional context involving several forms of empowerment and co-creation. It is this latter and aggregated capacity of the strategy aspect that will be used in the analysis

Journal of Data and Information Science of the empirical material, as this investigation centers on the users and not the municipality. 


\section{Results}

\subsection{The survey}

Demographics. In total 151 completed questionnaires were received. As seen from Table 2 below on age distribution, most respondents were in the age range of 36 to 65 , more specifically $24.50 \%$ in the group of 36 to 45 (37 respondents), $25.17 \%$ in the group of 46 to 55 (38 respondents), and $22.52 \%$ in the group of 56 to 65 (34 respondents). Another relatively well represented group was 26 - to 35-yearolds, making $17.22 \%$ ( 26 respondents). Least represented were the youngest (18 to 25 age range, $6.62 \%$ or 10 respondents) and the oldest (over $65,3.97 \%$ or 6 respondents).

Table 2. Age distribution.

\begin{tabular}{lccccccc}
\hline \multicolumn{1}{c}{ Age range } & $<18$ & $18-25$ & $26-35$ & $36-45$ & $46-55$ & $56-65$ & Over 65 \\
\hline Number of respondents & 0 & 10 & 26 & $\mathbf{3 7}$ & $\mathbf{3 8}$ & $\mathbf{3 4}$ & 6 \\
& $(0 \%)$ & $(6.62 \%)$ & $(17.22 \%)$ & $\mathbf{( 2 4 . 5 0 \% )}$ & $\mathbf{( 2 5 . 1 7 \% )}$ & $\mathbf{( 2 2 . 5 2 \% )}$ & $(3.97 \%)$ \\
Total & & & & $151(100 \%)$ & \\
\hline
\end{tabular}

Most participants identified themselves as researchers, $75.50 \%$ (114 participants), followed by $12.58 \%$ of students (19 participants), 9.27\% administrators (14 participants) and a few of the others: 1 retiree, 1 librarian, 1 administrative manager, and 1 project leader and education leader (4 in total or 2.65\%). Most respondents were from the Faculty of Arts and Humanities (29.80\%, 45 participants), followed by Faculty of Technology (24.50\% or 37 participants), and Faculty of Social Sciences (19.8\% or 30 participants). Less represented were School of Business and Economics (13.25\% or 20 participants) and Faculty of Health and Life Sciences (9.27\% or 14 participants). There were 5 colleagues from other institutions (3.97\%): 2 from the Office of External Relations, 1 from the University Library, 1 from the Department of Human Resources, and 1 from the Maintenance Unit.

The open question on the specific field of research or study (cf. section on survey above) was filled meaningfully by the total of 100 participants (60.24\% of all 151). Administrators do not research or study in any certain discipline; so the remainder of respondents included answers such as "xx", "." and similar. The 100 participants represented a range of subjects (see Figure 1): pedagogy and education (14), forestry and wood technology (7), political science (7), history (6), sociology (5), Swedish language (4), languages (4), business economics (4), media technology (4), informatics (3), statistics (3), computer science (3), music (3), media and journalism (3), literature (3), marketing (3), nursing (3), marine science (2), sport science (2), social work (2), labour economics (2), psychology (2), e-health (2), religion (1),

Journal of Data and Information Science

http://www.jdis.org https://www.degruyter.com/view/j/jdis 


\section{Research Paper}

geography (1), film studies (1), art (1), machine engineering (1), energy technology (1), national economics (1), industrial economics (1), and marine microbiology (1).

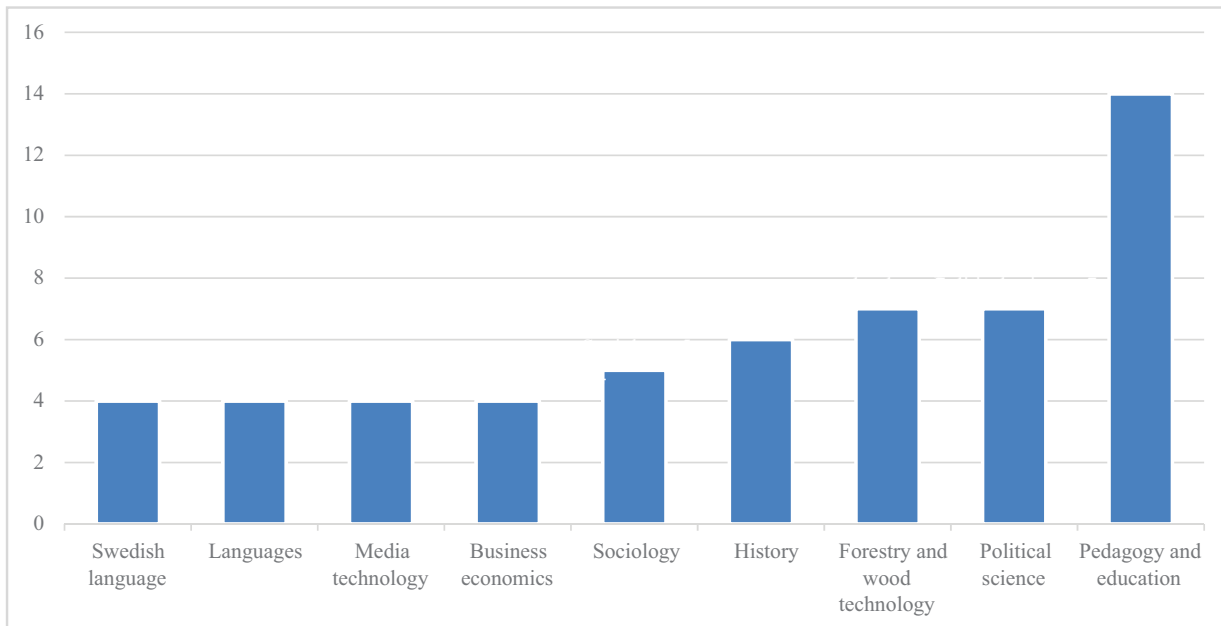

Figure 1. Most commonly represented disciplines ( $\mathrm{n}>3)$.

Most common potential uses of data sets. Figure 2 below shows the distribution of general categories of data provided by Växjö municipality, desired to be made available openly by the study participants. This question was of the "select all that apply" type. Most participants considered that category "Sustainability and environment / Inhabitant" would be of interest (51.66\% or 78 participants). This is not surprising considering Växjö's often heard title of the "the greenest city in Europe" due to its contemporary environmental policies. Of high interest are also "Preschool and school / Inhabitant" (45.70\% or 69 participants), "Municipality and politics / Inhabitant" (44.37\% or 67 participants), "Sustainability and environment / Business" (42.38\% or 64 participants). These are followed in popularity by "Building and living / Inhabitant" (40.40\% or 61 participants), "Traffic and social plans / Inhabitant" (39.74\% or 60 participants), "Experience and do / Inhabitant" (39.07\% or 59 participants), "Support and care / Inhabitant" $(38.41 \%$ or 58 participants), and "Search company / Business" (30.46\% or 46 participants). Of somewhat less interest seem to be "Power and develop / Business" $(25.17 \%$ or 38 participants), "Start a business / Business" (23.18\% or 35 participants), "Procurement and e-commerce / Business" (20.53\% or 31 participants), and "Land and premises / Business" (17.22\% or 26 participants).

The open question on how the data would be used received most replies related to research (69 cases). This could be expected, considering participants in the study. Information Science Specifically mentioned areas of research included: 1) big data; 2) education, 


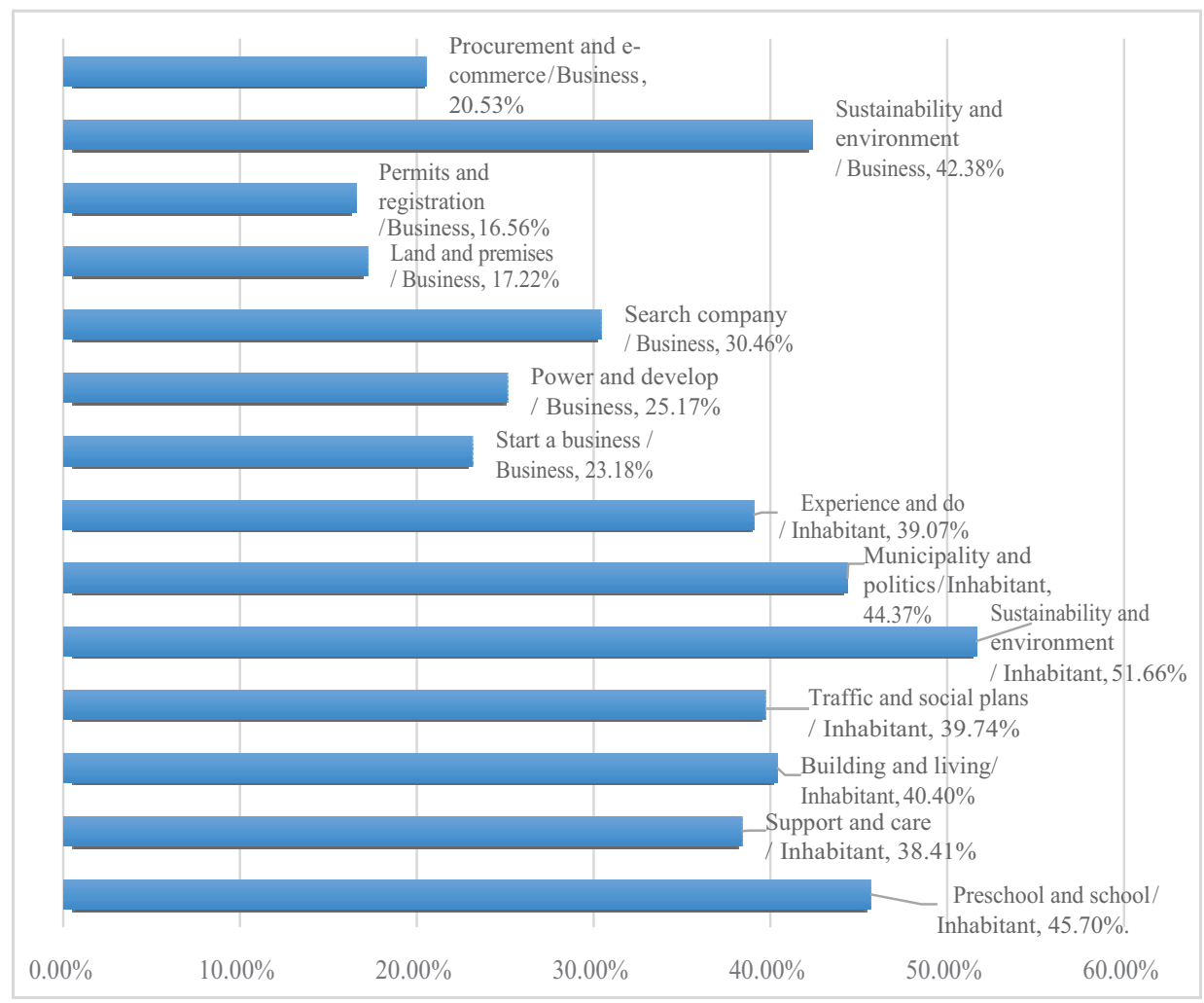

Figure 2. Desired categories for open data from the municipality.

educational outcomes, quality of pre-schools and schools, teaching methods, school achievement, pupils' language choices and the learning of multilingual pupils; 3 ) studies of language usage in certain social groups and contexts; 4) data on cultural events and the offer thereof, music, relationship between offer of cultural events, service and their use and development of society; 5) public management, public procurement, public policies and their conditions in the region; 6) environmental behaviour, how residents' behaviour affects the environment, heating needs, emissions from waste incinerators, use of biomass; 7) analysis of traffic flow (walking, biking, taking trains, driving cars), mapping energy use (electricity, heating, cooling, water); 8) immigration and integration, kindergartens and schools as a basis on which to study socio-economic living conditions; 8) wood construction; 9) political parties and political behaviour; 10) motivation for starting businesses.

Two more detailed examples illustrate the potential for open data use with specific use cases in research, across different areas:

Journal of Data and Information Science

http://www.jdis.org https://www.degruyter.com/view/j/jdis 


\section{Research Paper}

- "For example, study how political participation and trust in political institutions differ between different parts of Växjö municipality based on, for example, school results, community life and leisure activities. In addition, information on procurement and e-commerce would also constitute some form of a basis for, for example, the perception of corruption in the municipal sphere, etc."

- "My main area of research is sustainability and its related concepts such as social sustainability, supplier diversity, social and environmental policies and sustainable tourism and sustainable consumption for which the available data I indicated in previous question would be of great help as a secondary source of information for my different pieces of research".

The value of data for research in general has been illustrated by one particular comment emphasizing the need for researchers to get access to as much data as possible: "as representative for the faculty I am anxious that researchers are given as much and easy access as possible to as much data as privacy concerns allow". Another respondent noted that data can generate new research questions. Yet another one stated how he/she keeps his/her mind open for use of open data in the future, although his/her current research is theoretical.

Implications for development and informing policies were also emphasized with examples such as:

- "analyse and aim to provide guidelines/solutions for improvements in the areas";

- "...they would be used as a part of applied research effort in order to try and improve the society using ICT tools";

- "...conduct research that facilitate[s] people's awareness of their individual contributions towards common goals. To foster the establishing of common goals and connectedness";

- "to better understand sustainability in the region";

- to "build sustainable scenarios".

One commented that data are useful for development both at the societal level as well as personal one ("to find data that can be developing both for myself and for society"). Development of research tools to these purposes was also mentioned: "creating / prototyping interactive visualizations to browse open data and gain new insights".

Teaching was another common potential use listed by the respondents (23). This included specific mentions of student projects, final theses, practicing big data

Journal of Data and analysis, data visualisations and designing applications. As one participant put it, collected facts about the municipality may then be used in teaching, for example on 
sustainability, environment, cultural events and building the sense of belonging to the city among the pupils.

Being informed through data was given as a case by 11 participants. Another comment related to transparency and the fact that making data available is part of the law and is needed: "as a journalist and a democratic citizen, I want authorities to achieve as much transparency as possible".

Some listed individual reasons for their interest into Växjö's open data (5), such as: a personal interest into how to use these data as a tool for sustainable development; ability to better choose daycare; as an individual moving to Växjö it would be useful to have information on traffic; to increase one's knowledge about the municipality, adding that it is easier to make demands on the municipality if one has access to data. One person wrote the following: "I would use the 'Start a business' data to see which sector is potentially more successful to start my own business (i.e. what is required). I would use the 'Support and care' data to see the best medical institutions, so I can go to them. Getting the best health treatment is super important." One person also commented that he/she made the choice of categories as a researcher, and that when choosing as a private person, the choices would be different (how specifically was not mentioned).

There were four participants who proposed this as a resource when planning collaboration in the region; one respondent gave an example how he/she would use the data to get an overview of the companies in the region and find collaborative partners for research. There were two mentions of how the data could be used in work, one specifically: "as a journalist I would use the data for analysis and presentation to inform the inhabitants". The remainder stated they did not know how they would use the data (17), or that they would not find any of the data interesting (6).

Usefulness and usability of existing data sets. Coming to the next question on specific data sets already made available at a prototype portal at the time of survey, $19.21 \%$ (29 respondents) asserted that they found them useful, 50.33\% (76 participants) claimed that they would maybe find the data sets useful, while the remaining 30.46\% (46 respondents) considered them not useful. Illustrative examples of research use include: "...the more data is available, the smaller the resources that need to be invested by the researcher to collect the data..."; and a note by another one that this would help him/her acquire a better picture of trends in the community and heuristics from which to develop research questions.

Of those who selected "maybe" as a reply, the open question indicated that the reasons for this include: 1) no availability of data in English (3);2) this being the first time they see the data, making it hard for them to judge $(3)$; 3 ) the hard-to-use interface (3). The latter connects to the following question about whether the existing

Journal of Data and Information Science

http://www.jdis.org https://www.degruyter:com/view/j/jdis 


\section{Research Paper}

data sets could be presented in a more useful way. Here the opinion was approximately divided, with $48.34 \%$ suggesting yes (73 respondents), and 51.66\% who are happy with the current presentation (78 respondents). Of those who replied yes, 11 wrote that they actually did not know how to use the data. Organization of the interface was mentioned as a point for improvement by 8 respondents. Suggestions they gave included topical grouping, alphabetical listing, searching by keyword, visualisations based on maps and timelines, and general exploration support. Ten pointed to the need to generally improve the interface and make it more intuitive, more visually understandable and communicative. One emphasized the positive correlation between usability of the interface with transparency of the organisation at hand: "developing good and self-explanatory interfaces always helps. If the general public can easily find and collect data, then that would help the transparency of the organisation".

Three asked for more detailed and raw data (e.g. "The rawer the data the easier for researchers to make new runs, thus being able to ask new questions for the data"). Three other suggested summaries about each data set to help the user decide whether the detailed data are useful. Providing textual information to the data was asked for by six respondents, e.g. what are the units of measurements in tables and diagrams, how were the data collected etc. Four suggestions related to details on variables and data formatting, best summed up in the following comment by one of the participants: "The user must have access to all variables in a large list. One should then be able to choose from this list the desired variables that will then be exported to the user, who can choose from several different formats."

Two suggested help could be provided for those who are not trained in data analysis, one writing that he/she would appreciate education in how data can be analysed and used, which also implies the need for courses in this field. One also said that the service could be advertised and further discussed in a newsletter of network called Expansiva Växjö, a local network of those who wish to contribute to the development of the municipality.

The very last question was an optional one of the open type, asking for any further comments or suggestions related to Växjö municipality's open data. Of the 39 replies received $(25.83 \%)$, eight participants commented by praising the idea of open data made available by Växjö municipality, encouraging the municipality to continue with the good work. Three participants have pointed to the opportunity where open data may be used to further collaboration between Växjö municipality and the University. Two participants commented that it would be useful to have other municipalities' open data; one wrote that this would allow for comparative research across the whole country or its regions. 


\subsection{Analysis against the theoretical model}

So what can be learned from this? Many usability studies share the insight that the use of OD portals are still in its infancy. EDP's Open Data Maturity report from 2019 points out that the use frequency of national OD portals is still minor (EDP, 2019). Even if all 28 EU member states have such portals, only $16 \%$ have daily data requests being asked to the systems, $20 \%$ has weekly data requests, $24 \%$ monthly such, and 40\% even less than that (EDP, 2019).

The results of this study do not compare easily with other use cases, for example, the use cases that the European Data Portal (EDP) collects and presents. A quick look reveals that the use cases of the EDP take the form of short presentations of projects, with a minuscule description, some mentioning of intended benefits, and a few examples of how the data was used, without any foundation in systematic empirical investigations - the perspective, thus, being the developers' perspective, and not the users' (Publications Office of the European Union, 2020). This focus on the evaluation of portal systems rather than on the users' perception of the portals' usability is rather generalized. An OECD report broadly and internationally compares differences in usability related to OD portals' system affordances, not focusing on the perceived usefulness of the portals by the users (OECD, 2018). This is also the perspective of Máchová, Hub, and Lnenicka (2018), even though this study aims to adopt an ordinary citizen point of view in its analysis. Even Zhu and Freeman (2019) who developed a User Interaction Framework derive the framework's various criteria from a literature review rather than from empirical user studies (Zhu \& Freeman, 2019).

In the light of this, the theoretical model presented in 3.2 will be used to deepen the understanding of the study's results. The model, even if it is also based on different developing strategies rather than user studies, has the advantage of emanating from the same national context as the study in hand. A deeper understanding of the survey's results can be obtained by relating it to the four major aspects of the presented dual-approach model of local OGD strategies (described in section 3.2).

1. Target groups (technical expertise/companies versus local community and citizens). The respondents of the survey were predominantly researchers. This is a category of professionals that can be assumed to be early adopters of new technologies as well as to tend to contribute back to the society that finances their research. The results show that the respondents desired to a higher-degree various societal sectors datasets related to inhabitants rather than to business. Six out of eight of the most desired datasets were focused on the inhabitants, whereas a minority concerned the business sector. Data on 'Sustainability and environment', for example, was more desired in relation to inhabitants than in relation to business. Looking at the already published datasets, $51,6 \%$ of the respondents thought the presentation of the them was acceptable, whereas 48,34\% thought they could be presented better. This

Journal of Data and Information Science

http://www.jdis.org https://www.degruyter.com/view/j/jdis 


\section{Research Paper}

implies that a slight majority of respondents seems to be tech-savvy. The rather large minority that wants to see pedagogical adjustments to the presentation is potentially more interesting. This position implies a focus on the importance of a broader citizenry being able to use the datasets on its own terms. These two differing perspectives are also found in the respondents' free text statements. The call for more raw data, more various export formats, and more complex datasets, point to target groups with technological skills, whereas statements regarding the needs of visualisation and informing texts regarding the datasets focus on less tech-savvy target groups.

2. Desired practical outcomes (development of economically sustainable services versus empowered citizens' collaboration for public sector innovation). Looking at how the respondents want to use the datasets, there is a strong focus on research and teaching, corresponding to the composition of the respondents, but "collaboration in the region" is present as a small but tangible category. A majority of the use examples related to research focused on the public sector: education, public management, environmental behaviour of the citizens, traffic flows, immigration and integration, whereas only two focused on motivations for doing business and big data (which possibly relates more directly to business activities). Also, there is a social focus on informing municipal policy and raising awareness in the citizenry: open data could provide guidelines and suggestions for solutions, be used to better understand the conditions and build scenarios related to sustainability in the region, and contribute to people's awareness and identification as a local citizen. The majority of statements indicate the target groups as the municipality and its citizens, as well as the relations between them. Focus in terms of outcomes is on public innovation and citizen empowerment. On the other hand, the statement of applied research in order to improve society by developing ICT tools and solutions falls into another category. Here the focus is not so much on the local community; the emphasis on applied research and ICT-tools latently opens up for a business approach targeting entrepreneurs with economic services as outcomes. The latter strand is also visible in two respondents' statements that stress the need for more raw data and more variation in the data sets. This rather technical perspective implies that some respondents have a more thorough understanding of the need for various data sets in order to link them together in a varied new set of services.

3. General aim (open data platform for economic growth versus regional cooperation and co-creation of social growth). The development of commercial services is not particularly highlighted by the respondents, except possibly within the field of environment and sustainability where $42,38 \%$ of the respondents opted

Journal of Data and for a business perspective, whereas only $50 \%$ of them related to a broader citizens Information Science perspective within the same area. Besides from this, the overall pattern is that the 
majority of business related uses connects to between $25 \%$ to $17 \%$ of the respondents, whereas a broader perspective on inhabitants/citizens connects to $38 \%$ to $50 \%$ of the respondents.

4. Strategy (top down approach versus broader and more reflective approach). The expressed need for more raw and varied data (see also discussion under the second aspect above) exemplifies a position that connects to a general top-down strategy which focuses on engaging technical expertise, and on getting the infrastructure in place for development of services based on (linked) data sets. On the other hand, several statements express the need for improvement of the organisation and the presentation, of the data portal's interface, in a way that can be interpreted as an indirect focus on a broader and more inclusive strategy. This perspective is also present in the comments that call for training about the use of the data portal. This tentative analysis indirectly implies some general pointers regarding the problems in focus, the general aim, and the strategy regarding OGD. First, the two different approaches from the model are both expressed in the empirical results. In relation to the aspects of target groups, desired outcome, and general aim, the investigation seem to suggest a stronger social perspective in line with the Skellefteå-way rather than a Stockholm-way centred on businesses with the technical expertise. The survey's results regarding the relation between the two perspectives were less clear in relation to the strategy aspect, but both were present in the empirical material.

\section{Concluding remarks}

Generally, the idea of open data made available by Växjö municipality was considered a welcome one, albeit with space for further developments and improvements such as making more data sets available as well as more functionalities of the interface. Considering the very early stages of the portal, this is hardly surprising. In related research usability is considered crucial for uptake of OGD (Weerakkody et al., 2017) and data need to be presented in a range of formats and presentations for different types of users (Hossain \& Chan, 2015). Like in previous studies (e.g. Martin, Helbig, \& Birkhead, 2015), most respondents have never used an OGD portal before. Furthermore, even if awareness is there, the need for skills and training has been recognized in this as well as in other studies (Gascó-Hernándeza et al., 2018; Safarov, Meijer, \& Grimmelikhuijsen, 2017).

The study tentatively identifies two different but intermingled perspectives on OGD. One focuses on the technical potentials of combining various different open datasets, whereas the other's focus is on the community and OG. The study suggests that the Skellefteå-way is the most promising ground for successful future OG work: it maximises the outreach to potential stakeholders and at the same time

Journal of Data and Information Science

http://www.jdis.org https://www.degruyter:com/view/j/jdis 


\section{Research Paper}

it does not exclude the development of business-focused uses. A more explicit business strategy like the Stockholm-way runs the risk of alienating potential popular stakeholders in its focus on experts within commercial firms.

Since the survey was conducted, the data portal has been replaced with a webservice on open geographical data only with similar features for data use as the previous service (https://data-vaxjo.opendata.arcgis.com/search). In line with available funding, the nature of the study was exploratory and implemented as an anonymous web-based survey of employees and students at the local university. Further research involving (qualitative) surveys with all stakeholders would allow for creating a more complete picture of the matter at hand.

\section{Author contributions}

Koraljka Golub (koraljka.golub@Inu.se) led and analyzed the survey, Arwid Lund (arwid.lund@sh.se) outlined the theoretical model and analyzed the survey results against it. Arwid also provided the background on OGD while they both wrote the related research together and reviewed the manuscript.

\section{References}

Baack, S. (2015). Datafication and empowerment: How the open data movement re-articulates notions of democracy, participation, and journalism. Big Data Society, July-December 2015, $1-11$.

Bergsman, L.G. (2020). Hur länge har kommunen haft sin portal för öppna data? [Personal communication].

Borgman, C.L. (2015). Big data, little data, no data: Scholarship in the networked world. Cambridge, Ma.: MIT Press.

DIGG. (2019a). Uppdrag att öka den offentliga förvaltningens förmåga att tillgängliggöra öppna data, bedriva öppen och datadriven innovation samt använda artificiell intelligens (Dnr: 2019139; Delrapport i regeringsuppdraget I2019/01416/DF samt I2019/01020/DF (delvis), p. 14). https://www.digg.se/4a3a84/globalassets/dokument/publicerat/publikationer/delrapportoppna-data-oppen-och-datadriven-innovation-samt-ai.pdf

DIGG. (2019b). Förvaltnings- och finansieringsförslag för dataportal.se: Bilaga 2 till Delrapport avseende regeringsuppdrag rörande öppna data, öppen och datadriven innovation samt AI (Dnr: 2019-139; p. 11). Myndigheten för digital förvaltning.

DIGG. (2020). Principer för att tillgängliggöra information-DIGG. DIGG - Myndighet. https:// www.digg.se/utveckling-av-digital-forvaltning/sveriges-dataportal/principer\#princip_6: dokumentera_och_beskriv_information

Frick, A. (2015). Öppna data: En omvärldsanalys med nulägesstatus. Internetstiftelsen.

Gascó-Hernándeza, M., Martin, E.G., Reggi, L., Pyo, S., \& Luna-Reyes, L.F. (2018). Promoting the use of open government data: Cases of training and engagement. Government Information

Journal of Data and Information Science

\section{Quarterly, 2(35), 233-42.}


Gruen, N. (2009). Engage: Getting on with government 2.0 report of the government 2.0 taskforce. Retrieved June 15, 2018, from http:/www.finance.gov.au/sites/default/files/Government20TaskforceReport.pdf? $v=1$

Harrison, T.M., Pardo, T.A., \& Cook, M. (2012). Creating open government ecosystems: A research and development agenda. Future Internet, 4(4), 900-28.

HM Treasury. (2009). Putting the frontline first: Smarter government. London: HM Government; 2009. Retrieved June 15, 2018, from https://www.gov.uk/government/uploads/system/ uploads/attachment_data/file/228889/7753.pdf

Hossain, M., \& Chan, C. (2016). Open data adoption in Australian government agencies: An exploratory study. In F. Burstein, H. Scheepers, \& G. Deegan (Eds.), Australasian Conference on Information Systems (ACIS) 2015. Retrieved June 15, 2018, from https://arxiv.org/abs/ 1606.02500

Kalin, I. (2014). Open data policy improves democracy. SAIS Review of International Affairs, 34(1), 59-70.

Kitchin, R. (2014). The data revolution: Big data, open data, data infrastructures and their consequences. Los Angeles, Ca.: SAGE.

Lassinanti, J., Bergvall-Kåreborn, B., \& Ståhlbröst, A. (2014). Shaping local open data initiatives: Politics and implications. Journal of Theoretical and Applied Electronic Commerce Research, 9(2), 17-33.

Lee, G., \& Hoon Kwak, Y. (2011). An open government implementation model: Moving to increased public engagement. Retrieved June 15, 2018, from http:/www-07.ibm.com/events/ au/smartergovernment/pdf/An_Open_Government_Implementation_Model.pdf

Liljeqvist, P., Nordfeldt, A., Warnolf, A., \& Holmdahl, C. (2020). Innovation genom information: Huvudbetänkande av Öppna data-utredningen (SOU 2020:55; Statens Offentliga Utredningar).

Manyika, J., Chui, M., Groves, P., Farrell, D, Van Kuiken, S., \& Doshi E.A. (2013). Open data: Unlocking innovation and performance with liquid information. San Francisco, Ca.: The McKinsey Global Institute.

Martin, E.G, Helbig, N., Birkhead, G.S. (2015). Opening health data: What do researchers want?: Early experiences with New York's open health data platform. Journal of Public Health Management and Practice, 21(5), 1-7. Retrieved from http://www.ncbi.nlm.nih.gov/pubmed/ 25105279

Máchová, R., Hub, M., \& Lnenicka, M. (2018). Usability evaluation of open data portals: Evaluating data discoverability, accessibility, and reusability from a stakeholders' perspective. Aslib Journal of Information Management, 70(3), 252-268. https://doi.org/10.1108/AJIM-02-20180026

Milan, S., \& Gutiérrez, M. (2015). Medios ciudadanos y big data: la emergencia del activismo de datos. Mediaciones, 14(11), 10-26.

OECD. (2018). Open Government Data Report: Enhancing policy maturity for sustainable impact (OECD Digital Government Studies). OECD Publishing.

OECD. (2019). Government at a Glance 2019 | en | OECD. http://www.oecd.org/gov/governmentat-a-glance-22214399.htm

Open Government Partnership. (2018). About OGP: Open Government Partnership. Retrieved from https://www.opengovpartnership.org/about/about-ogp

Journal of Data and Information Science

http://www.jdis.org https://www.degruyter:com/view/j/jdis 


\section{Research Paper}

Publications Office of the European Union. (2019). Open data maturity report 2019. Publications Office. https://data.europa.eu/doi/10.2830/073835

Publications office of the European Union. (2020). Användningsfall | Europeiska Data Portalen. Användningsfall Europeiska Data Portalen. https://www.europeandataportal.eu/sv/impactstudies/use-cases

Safarov, I., Meijer, A., \& Grimmelikhuijsen, S. (2017). Utilization of open government data: A systematic literature review of types, conditions, effects and users. Information Polity 22(1), 1-24.

Shekarabi, A., \& K. Aldén. (2016). Uppdrag till Riksarkivet att främja statliga myndigheters arbete med att tillgängliggöra data för vidareutnyttjande. Retrieved from https://riksarkivet.se/ Media/pdf-filer/uppdrag-till-Riksarkivet_16juni2016.pdf

Skellefteå Kommun, S. (2018). Kommunfakta. Kommunfakta. https://www.skelleftea.se/kommun/ om-skelleftea

Ubaldi, B. (2013). Open government data: Towards empirical analysis of open government data initiatives (Rep. No. 22). Paris: OECD Publishing.

Växjö kommun. (2020). Växjö kommun-Öppna geografiska data. https://data-vaxjo.opendata. arcgis.com/

Weerakkody, V., Kawaljeet, K., Balta, M.A., Irani, Z., \& Dwivedi, Y.K. (2017). Factors influencing user acceptance of public sector big open data. Production Planning \& Control, 28(11-12), 891-905.

White House. (2009a). Memorandum on transparency and open government. Washington, DC: White House.

White House. (2009b). Memorandum on freedom of information act. Washington, DC: White House.

Zhu, X., \& Freeman, M.A. (2019). An evaluation of U.S. municipal open data portals: A user interaction framework. Journal of the Association for Information Science and Technology, 70(1), 27-37. https://doi.org/10.1002/asi.24081

\section{(c) $\odot \odot \odot$}

This is an open access article licensed under the Creative Commons Attribution-NonCommercialNoDerivs License (http://creativecommons.org/licenses/by-nc-nd/4.0/).

Journal of Data and Information Science 